\title{
Vascular Disease in the Metabolic Syndrome: Do We Need to Target the Microcirculation to Treat Large Vessel Disease?
}

\author{
Andrew J. Krentz Geraldine Clough Christopher D. Byrne \\ Institute of Developmental Sciences, School of Medicine, University of Southampton, Southampton General \\ Hospital, Southampton, UK
}

\section{Key Words}

Metabolic syndrome $\cdot$ Microvasculature $\cdot$ Atherosclerosis .

Diabetes mellitus $\cdot$ Impaired glucose tolerance

\begin{abstract}
The metabolic syndrome of vascular risk is threatening large numbers of ever-younger people. To date, the syndrome has been chiefly viewed as a potential risk marker that confers a heightened probability of developing type 2 diabetes and occlusive atherothrombotic disease of large- and mediumsized arteries. Accumulating evidence suggests that the components of the metabolic syndrome may also adversely affect the microvasculature through several inter-related mechanisms. These include the following observations: classic risk factors for macrovascular disease such as high blood pressure and dyslipidaemia also accelerate microvascular complications of diabetes, lesser disturbances of glucose metabolism (i.e. impaired glucose tolerance) may be associated with some forms of microvascular dysfunction, nonglucose intermediary metabolites may promote renovascular hypertension thereby damaging the microvasculature, and insulin resistance appears to be directly associated with
\end{abstract}

Previous articles in this special topic series: 1. Pohl U, Meininger G: Editorial. J Vasc Res 2009;45:503. 2. Hudlicka O, Brown MD: Adaptation of skeletal muscle microvasculature to increased or decreased blood flow: role of shear stress, nitric oxide and vascular endothelial growth factor. J Vasc Res 2009;46:504-512.

\section{KARGER}

Fax +41613061234 E-Mail karger@karger.ch www.karger.com (c) 2009 S. Karger AG, Basel

$1018-1172 / 09 / 0466-0515 \$ 26.00 / 0$

Accessible online at:

www.karger.com/jvr microvascular dysfunction. In turn, microvascular complications such as nephropathy and autonomic neuropathy may promote the development and progression of atherosclerosis. We argue that the vascular implications of the metabolic syndrome should be broadened to include the microvasculature. The hypothesis that vascular events can be prevented, or at least deferred, through earlier therapeutic intervention in pre-diabetic subjects with glucose intolerance is amenable to testing in clinical trials.

Copyright $\odot 2009$ S. Karger AG, Basel

\section{Introduction}

The term 'metabolic syndrome' (International Classification of Disease 9th revision code 277.7) refers to an increasingly prevalent clustering of known risk factors for atherosclerotic cardiovascular disease $[1,2]$. Key components of the syndrome include:

- Central obesity

- Dyslipidaemia - hypertriglyceridaemia and low levels of high-density lipoprotein (HDL) cholesterol

- High blood pressure

- Impaired glucose metabolism

Observational data suggest that the syndrome, as presently defined, confers approximately a 3 -fold increased

A.J.K. and C.D.B. have received research funding from pharmaceutical companies involved with cardiovascular and diabetes therapy.

Prof. Geraldine Clough

The Institute of Developmental Sciences (IDS Building)

University of Southampton, MP 887, Southampton General Hospital

Tremona Rd, Southampton SO16 6YD (UK)

Tel. +44238079 4292, Fax +44238079 5255/5256, E-Mail G.F.Clough@soton.ac.uk 
Table 1. Established and putative mechanisms for microvasculopathy in the metabolic syndrome

High blood pressure

Promotes development and progression of endothelial

dysfunction, retinopathy and nephropathy

Dyslipidaemia

Endothelial dysfunction; accelerates progression of nephropathy

Glucose intolerance

Classic microvascular complications reportedly associated with impaired glucose tolerance

Non-glucose intermediary metabolites

Succinate and $\alpha$-ketoglutarate may promote renovascular hypertension

Obesity-associated insulin resistance

Evidence for an association with microvascular dysfunction in skeletal muscle

risk of occlusive cardiovascular disease [3] in affected subjects; the risk of developing type 2 diabetes is even higher [4]. Insulin resistance, linked to obesity and defined in generic terms as reduced biological action of the hormone, is widely - although not unanimously - regarded as a fundamental defect underpinning the clustering of cardiovascular disease risk factors. However, rather than directly addressing the issue of impaired insulin action, current approaches to the management of the syndrome hinge on ameliorating the various metabolic, haemodynamic and rheological defects that conspire to elevate the risk of adverse clinical events (table 1) $[1,4]$. With the rapid increase in the global prevalence of obesity that is currently in progress, the syndrome threatens to affect large numbers of ever-younger people. Of concern, subjects who manifest the metabolic syndrome in childhood [5], adolescence [6] or early adulthood will be exposed for decades to potent vascular risk factors that are, by definition, present in combination $[7,8]$. The available evidence suggests a high propensity for serious complications in subjects with early-onset type 2 diabetes [9].

While the clinical consequences of the metabolic syndrome primarily reflect increased rates of atherothrombotic events, evidence is accumulating from epidemiological and experimental research that the microvasculature may also be under threat. Daily clinical experience teaches us that interactions between disturbances in the microvasculature and macrovasculature often conspire to the detriment of affected patients. We consider that both of these vascular territories are relevant to adverse clinical outcomes. In this article we re- view the literature on this topic and consider the potential benefits of taking a broader approach to the prevention of vascular disease, i.e. one that encompasses both microvascular and macrovascular dysfunction together, wherever possible.

\section{Does Microvascular Dysfunction Promote Atherosclerosis?}

Among patients with diabetes, it is well accepted that small and large vessel disease frequently coexist. This has been amply documented in large observational studies, for example that of Pirart [10] and interventional clinical trials such as the United Kingdom Prospective Diabetes Study (UKPDS) [11]. Vascular complications often develop in multiple tissues in a complex web wherein one complication can promote the development and/or progression of others [12]. The close and often catastrophic association between diabetic nephropathy and atherosclerosis is perhaps the best-known example of this kind of interaction between small and large vessel disease. Thus, a high proportion of patients with progressive renal disease arising as a consequence of diabetic nephropathy succumb to fatal macrovascular events, usually myocardial infarction and its sequelae, well before they reach end-stage renal failure [13]. In turn, nephropathy-associated hypertension accelerates the loss of glomerular function and promotes the development and progression of retinopathy [14]; in parallel, progressive uraemia adversely affects the function of peripheral and autonomic nerves [15]. In this way, a matrix of microvascular and macrovascular dysfunction creates a vicious cycle resulting in progressive tissue damage [16].

\section{Shared Mechanisms of Vascular Damage Affecting Small and Large Vessels}

While current data support a relationship between microcirculation and the metabolic syndrome, the direction, in terms of cause and effect, remains uncertain [17]. What is becoming increasingly clear is that shared mechanisms initiate and sustain dysfunction in small and large blood vessels alike. Early pathological events, notably cellular inflammatory changes, are similar in both the macro- and microcirculations (i.e. those vessels under $\sim 100 \mu \mathrm{m}$ in diameter). Furthermore, it has been hypothesized that changes within the microcirculation may 
serve to drive the development and progression of atherosclerosis in medium and large arteries (see below) [18]. Support for this hypothesis is largely confined to animal experiments. In the obese Zucker rat, a model of the metabolic syndrome, hind limb blood flow is reduced leading to a remodelling of microcirculation in favour of smaller, less distensible vessels [19]. It is suggested that this remodelling may limit maximum perfusion capacity and, as a result, contribute to the progression of peripheral microvascular disease. In obese Zucker rats that manifest features of the metabolic syndrome, skeletal muscle microvessel rarefaction appears not to depend on elevated mean arterial pressure. This raises the possibility that other factors associated with the metabolic syndrome, perhaps insulin resistance, might underlie the progressive reduction in microvessel density in these animals [20]. In humans, obesity and insulin resistance within insulin-sensitive tissues, such as skeletal muscle, are associated with dysregulation of vascular function and a loss of insulin-mediated capillary recruitment [21, 22]. Features of the metabolic syndrome are also recognised to predispose to a reduced microvascular density or rarefaction [23] that may contribute to an increase in vascular resistance and to an impaired exchange capacity. Together, these factors will serve to limit solute delivery to the tissue and to increase solute diffusion distances between the vascular and cellular compartments. In type 2 diabetes, many factors may contribute to microvascular dysfunction, including impaired endothelium-dependent vasodilation $[24,25]$, reduced capillary recruitment [26] and lower capillary density [27]. Moreover, the increased glycation of erythrocyte membrane proteins causing rigidity may also increase resistance to travel through the circulation [28]. Furthermore, concomitant alterations of the endothelial cell surface glycocalyx may also modulate shear, endothelial permeability and exchange surface area [29].

Although the quantitative significance of the microcirculation to atherogenesis is uncertain the total surface area of the microvasculature i.e. arterioles, capillaries and post-capillary venules is vastly greater than that of larger vessels. This implies that even low-level activation of the microvascular endothelium could have a large net effect in vivo [18]. Of note in the context of this hypothesis, it has been postulated that defects in post-prandial myocardial microvascular perfusion, assessed using myocardial contrast echocardiography, might be an early indicator of coronary artery disease in patients with type 2 diabetes [30].

Metabolic Syndrome and Vascular Disease

\section{Microvascular and Macrovascular Disease Share Similar Risk Factors}

We have recently reviewed the literature concerning the clinical implications of microvascular and macrovascular interactions in human diseases [31]. Shared mechanisms and risk factors drive the development and progression of both small and large vessel disease [31]. Contrary to traditional clinical distinctions, risk factors for atherosclerosis may have important implications for the development of the microvascular complications of diabetes. For example, it is noteworthy that forms of progressive glomerulosclerosis share risk factors with atherosclerosis and have histopathological similarities to atheroma [32]. It should perhaps come as little surprise that factors such as high blood pressure and abnormal lipid profiles exert adverse effects on small and large blood vessels alike. Thus, classic atherosclerosis risk factors such as hypertension [33] and disturbed lipoprotein metabolism [34, 35] also contribute to damage of the ocular microvasculature. The overlap between risk factors for small vessel disease and atherosclerosis was illustrated by a report from the European Diabetes (EURODIAB) Prospective Complications Study: among patients with type 1 diabetes, distal peripheral neuropathy - traditionally regarded as a microvascular complication of diabetes - was associated with classic risk factors for atherosclerosis that included raised serum triglycerides, elevated body mass index, smoking and hypertension [36]. It is apparent that some individuals with type 1 diabetes can also have features of the metabolic syndrome; these patients may be more prone to vascular complications [37]. This appears to be in accordance with a number of observational studies that suggest that patients who have the metabolic syndrome in concert with type 2 diabetes have a higher frequency of microvascular complications [38-40]. In the large Metascreen study conducted in Italy, for example, the metabolic syndrome was independently associated with both macro- and microvascular complications of diabetes [41]. However, not all studies have confirmed this association, a notable exception being the UKPDS [42]. Whether the metabolic syndrome can initiate or potentiate microvascular disease independently of the degree and duration of the major primary driver to microvascular disease, i.e. chronic hyperglycaemia at levels diagnostic of diabetes, remains unclear. Such conclusions cannot be reliably drawn from cross-sectional casecontrol studies in which antecedent glycaemic control is not known with certainty. Randomized clinical trials with careful evaluation of microvascular endpoints would be required to rigorously test this hypothesis.

J Vasc Res 2009:46:515-526 


\section{Glucose Intolerance: A Novel Risk Factor for Microvascular Disease?}

Current diagnostic criteria for diabetes denote thresholds of chronic hyperglycaemia beyond which the risk of classic microvascular complications - notably retinopathy - increases dramatically $[43,44]$. In contrast, while diabetes confers an increased risk of macrovascular disease of approximately 2 - to 4 -fold $[45,46]$, no clear glycaemic threshold for the development of atherosclerosis has been identified in population-based studies $[47,48]$. It is well established that categories of dysglycaemia that lie below the diagnostic thresholds for diabetes, i.e. impaired glucose tolerance (IGT) and impaired fasting glucose, are associated with an increased long-term risk of macrovascular disease [49]. The impact of these lesser degrees of hyperglycaemia on microvascular disease has recently come under scrutiny. Singleton et al. [50] have suggested that chronic glucose intolerance might have clinically significant adverse effects on microvascular function. Theoretically, mitochondrial superoxide formation during acute spikes of hyperglycaemia in subjects with IGT could lead to intermittent endothelial dysfunction [51]. Rapid increases in circulating glucose and lipid levels trigger carbonyl stress which through independent pathways or by potentiating oxidative stress may contribute to generalised vasculopathy [52]. A recent clinical study demonstrated evidence of endothelial dysfunction and increased oxidative stress in subjects with IGT and impaired fasting glucose [53]. However, several caveats should be borne in mind when considering whether glucose intolerance causes or promotes clinically relevant microvascular disease. First, while certain microvascular retinal abnormalities have been reported in pre-diabetic individuals and mounting evidence that endothelial dysfunction and inflammation are involved in the development of retinal microvascular changes [54], the classic pathological features of diabetic retinopathy, such as capillary microaneurysms, have generally been absent $[55,56]$. Second, it is uncertain whether chronic polyneuropathy [57] can be regarded as a wholly reliable model of diabetic microvascular disease. Even among patients with diabetes, a potent cause of neural dysfunction, distal polyneuropathy is recognized to be heterogeneous [58] and its pathogenesis may have more direct metabolic components $[59,60]$. Whilst IGT is common in patients with peripheral neuropathy the extent to which impaired glucose metabolism directly causes nerve injury as opposed to being a covariant with other factors remains to be determined [61]. Third, the picture is unclear with respect to another common manifestation of long-term diabetes - erectile dysfunction. This symptom is sometimes attributed to generalized autonomic neuropathy, especially if there is clinical evidence of distal polyneuropathy. However, the function of the erectile vasculature is regarded as being especially vulnerable to detrimental effects of endothelial dysfunction $[62,63]$. Longitudinal studies show that the development of erectile dysfunction is predicted by classic risk factors for macrovascular disease [64].

Thus, additional data from animal and human studies are required before the thesis that glucose intolerance directly causes microvascular disease typical of that associated with diabetes can be accepted. However, it is well recognized that established microvascular and macrovascular damage is often encountered at diagnosis of type 2 diabetes, as observed in the UKPDS [65]. The most widely accepted explanation for this phenomenon is that undetected chronic hyperglycaemia in the diabetic range has led to tissue complications [66]. Whether antecedent glucose intolerance might contribute independently to microvascular dysfunction is presently unclear.

\section{A Pathogenic Role for Non-Glucose Intermediary Metabolites?}

As far back as the 1970s, it was proposed that derangements of circulating intermediary metabolites might contribute to the long-term vascular damage associated with diabetes [67]. A recent report updates this suggestion by demonstrating that certain intermediates of the citric acid cycle may promote renovascular hypertension through novel cellular mechanisms [68]. GPR91, a previously orphan G-protein-coupled receptor, functions as a receptor for succinate while GPR99, a relative of GPR91, responds to $\alpha$-ketoglutarate. Acting as ligands for G-protein-coupled receptors, succinate and $\alpha$-ketoglutarate have unexpected signalling functions. In the same paper, the investigators showed that succinate can increase blood pressure in animals, an effect that involves activation of the renin-angiotensin system (RAS). Thus, a potential role emerges for GPR91 in renovascular hypertension, which in turn is closely linked to vascular disease, diabetes and renal failure. A putative role of mitochondrial dysfunction, the site of citric acid cycle activity, in the pathogenesis of type 2 diabetes requires further clarification [69]. 


\section{Impact of Insulin Resistance on Microvascular Function}

Abnormalities in arteriolar reactivity, capillary recruitment, permeability and haemorheology have been reported features in the metabolic syndrome [17]. Recent studies in humans and animals have provided clear evidence of a direct link between insulin resistance and impaired microvascular function [70]. In obese insulin-resistant women, De Jongh et al. [21] examined microvascular responses and found impaired skin capillary recruitment and endothelium-independent vasodilatation. A correlation was observed between capillary recruitment and whole-body insulin sensitivity, measured using the glucose clamp technique. Using an invasive investigative approach, these investigators also demonstrated impairment of intramuscular microvascular function during exogenous insulin infusion in healthy volunteers [71]. These results, and others in cohorts of atrisk individuals [72], raise the possibility that capillary dysfunction in a key insulin-responsive tissue, namely skeletal muscle, might contribute to whole-body insulin resistance thereby promoting the development of the metabolic syndrome. Furthermore, it is suggested that the early consequences of hyperglycaemia on microvascular function, including activation of protein kinase $\mathrm{C}$ and increased anti-oxidant formation, might be exacerbated by pre-existing obesity [73]. Studies in the obese Zucker rat suggest that chronic reductions in nitric oxide bioavailability, in part mediated by scavenging actions of oxidative free radicals, may contribute to loss of skeletal muscle microvessels and, hence, impaired muscle perfusion [74]. Adipocyte products have come under scrutiny as modulators of microvascular function. Studies in nondiabetic women have demonstrated that non-esterified ('free') fatty acids (NEFA) impair microvascular function in the skin [75]; NEFA concentrations are elevated in obesity-associated insulin resistance [76], and a hypothetical role for NEFA in obesity-associated insulin resistance, hypertension, and microangiopathy has been proposed. Adipocytokines are hormones produced by adipocytes, the circulating concentrations of which are altered in insulin-resistant states [77]. There is some evidence that leptin activates human platelets and can limit transendothelial cell diffusion whereas adiponectin influences endothelial cell permeability [78]. In contrast, the non-adipocyte hormone ghrelin, which like leptin and adiponectin exerts central nervous system effects on energy balance [79], appears to be devoid of similar activity [78]. The effects of these hormones on microcirculatory blood flow has been examined in a primate model with results providing support for modulatory actions of leptin and adiponectin, with the data for ghrelin being more equivocal [80].

A heritable component of insulin resistance on microvascular complication of diabetes has been proposed. In a report from the Genesis France-Belgium Study, composite insulin resistance scores, which included vascular risk factors such as high blood pressure and diabetes, were higher in relatives of probands with type 1 diabetes who had diabetic retinopathy or nephropathy compared to those without these complications [81]. Low birth weight also predisposes to vascular disease in later life [82]. Several studies have demonstrated a link between low birth weight and endothelial dysfunction in young adults [83, 84], children [85, 86] and infants [87].

\section{Therapeutic Implications}

Health economic analyses show that the highest costs incurred in diabetes care apply to patients who have a combination of microvascular and macrovascular complications [88]. In our view, the increasing prevalence of the metabolic syndrome strengthens the case for using therapies proven to reduce atherosclerotic events and $\mathrm{mi}-$ crovascular disease in parallel wherever feasible (table 2). While non-pharmacological measures, i.e. dietary modification and adequate levels of physical exercise, are regarded as the foundation of vascular disease prevention, it is recognized that many patients will not achieve their therapeutic goals in the absence of drug therapy [89]. Current evidence supports the existence of a reciprocal relationship between endothelial dysfunction and insulin resistance that may link cardiovascular and metabolic diseases [90]. Some drugs used in patients with diabetes may have favourable effects on microvascular function that may extend beyond their capacity to lower blood glucose concentrations. Further investigation of these putative effects is warranted.

\section{Insulin Therapy}

In the UKPDS [11], patients with type 2 diabetes treated with insulin experienced a reduced risk of onset and progression of microvascular complications. Insulin has vasodilatory properties which, through augmented muscle blood flow, may reduce insulin resistance by enhancing cellular glucose uptake [91]. Recent evidence supports an early direct effect of insulin on microvascular function in skeletal muscle mediated through a nitric oxide 
Table 2. Selected drug interventions for the prevention of macrovascular and microvascular disease associated with the metabolic syndrome

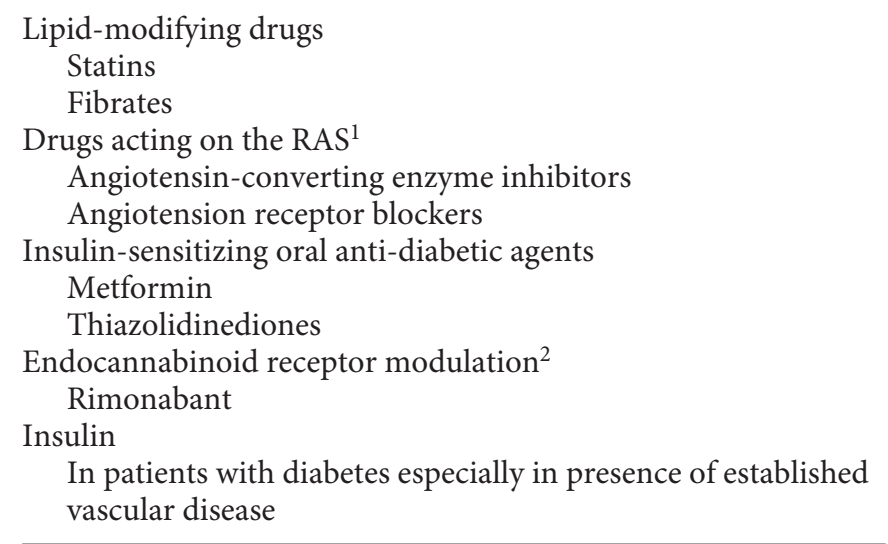

Lifestyle measures should be regarded as first-line wherever possible.

${ }^{1}$ As part of anti-hypertensive regimens aimed at attaining target blood pressure levels, these drugs are preferred to $\beta$-blockers and diuretics in the context of the metabolic syndrome.

${ }^{2}$ No outcome studies for vascular disease are available for this agent; rimonbant was withdrawn from the European market in 2008 .

(NO)-dependent mechanism that regulates glucose disposal in vivo [92]. Insulin also has favourable effects of local expression of the plasminogen activator inhibitor-1 which retards fibrinolysis in the coronary vasculature of patients with diabetes [93]. In addition, the anti-inflammatory effects of insulin may mediate vascular protective effects; thus, C-reactive protein levels are reduced by insulin therapy [94]. Clinical trials have shown improvements in surrogate markers of atherosclerosis, i.e. endothelial function [95] and measures of aortic waveforms [96] in patients with type 2 diabetes treated with insulin.

\section{Lipid-Modifying Drugs}

Statins reduce inflammation and prevent cardiovascular events in patients with or without diabetes [97-100]. Theoretically, these drugs could have implications for the prevention of microvasculature disease $[34,101]$ and for insulin action [102]. Evidence supporting the former hypothesis comes from the recent Fenofibrate Intervention and Event Lowering in Diabetes (FIELD) study. Among patients with type 2 diabetes, the peroxisome proliferator-activated receptor (PPAR)- $\alpha$ agonist fenofibrate reduced the requirement for ocular laser treatment (5.2 vs.
$3.6 \%, p=0.0003)$ and retarded the progression of microalbuminuria $(p=0.002)$ [35]. However, not all lipid-modifying drugs have been shown to have beneficial effects on vascular events even when lipids are favourably altered $[72,103]$, a notable example being the novel cholesteryl ester transfer protein inhibitor torcetrapib [104] (see below: Drugs in Development).

\section{RAS Blockade}

Hypertension exacerbates retinopathy and nephropathy as well as being an important modifiable risk factor for atherosclerosis. Effective control of hypertension reduced the risk of microvascular complications in the UKPDS [105]. Intervention with anti-hypertensive drugs at an early stage might theoretically avoid irreversible vascular remodelling and permanent tissue damage [106]. Moreover, angiotensin-converting enzyme inhibitors and angiotensin receptor blockers are associated with a reduction in the incidence of new-onset diabetes among patients with essential hypertension [107]. A notable exception was the Diabetes Reduction Assessment with Ramipril and Rosiglitazone Medication (DREAM) in which ramipril did not prevent the progression to diabetes in subjects with IGT or impaired fasting glucose [108]. However, in support of the hypothesis that angiotensinconverting enzyme inhibitors might protect against the development of diabetes, the rate of regression to normoglycaemia was increased by rampiril. The ongoing Nateglinide and Valsartan in Impaired Glucose Tolerance Outcomes Research (NAVIGATOR) study should help clarify the vascular benefits of initiating treatment aimed at blocking the RAS using an angiotensin receptor blocker in pre-diabetic subjects with glucose intolerance.

\section{Insulin-Sensitizing Drugs}

Metformin is regarded as a cardioprotective anti-diabetic drug [109] that may also have beneficial actions on the microvasculature [110]. Beneficial effects of metformin on microvascular and macrovascular complications of diabetes were recently confirmed in a 10-year followup of overweight participants in the UKPDS who were originally randomized to the drug as monotherapy [111]. Thiazolidinediones are synthetic ligands for the PPAR- $\gamma$ receptor [112]. These drugs have multiple effects on aspects of the metabolic syndrome [113] that may protect against microvascular disease [114]. Insulin-sensitizing drugs may also modulate microvascular function independently of the effects on metabolic control [115], e.g. via anti-proliferative effects [116] and reduction of oxidative stress with modulation of vascular tone via changes in 
NO bioavailability [117]. In addition to the effects on the vasculature, thiazolidinediones, like metformin [118], may also prevent, or at least defer, the development of type 2 diabetes [119] through effects on insulin action and, more speculatively, preservation of $\beta$-cell function $[120,121]$. The Prospective Pioglitazone Clinical Trial In Macrovascular Events (PROactive) study, is the first trial to examine the impact of a thiazolidinedione on cardiovascular events [122]. While the primary composite endpoint of cardiovascular events, including leg revascularization, did not attain statistical significance $(\mathrm{p}=0.095)$, the main secondary endpoint (all-cause mortality, nonfatal MI and stroke) was significant (hazard ratio 0.84, $95 \%$ confidence interval $0.72-0.98, p=0.027$ ). However, concerns about the validity of the secondary endpoint analysis, hospital admissions for heart failure (a non-adjudicated adverse event) and weight gain, generated uncertainties about the clinical implications of this trial [123]. In 2007, a controversial meta-analysis suggested that rosiglitazone significantly increases the risk of myocardial infarction [124]. Further analyses have lent support to this possibility [125]. In contrast, the balance of evidence for pioglitazone is in favour of a protective effect on cardiovascular events $[122,126]$. However, both drugs carry the aforementioned risk of heart failure in vulnerable patients [127]; an increased risk of distal fractures has also been reported in women [128].

Reducing the need for polypharmacy is a pressing aspect of the therapeutic challenge [129]. Using insulin sensitizers is an attractive option in pursuit of this goal, particularly if the risk to benefit ratio of these drugs could be improved. However, several agents in a new class of combined PPAR- $\alpha$ and $-\gamma$ agonists (glitazars) have already been terminated in the late stages of development due to a range of toxicity issues including adverse cardiovascular effects [130]. Whether new approaches such as activators of the PPAR- $\delta$ receptor will prove to be safe and effective has yet to be established [131].

\section{Anti-Obesity Drugs}

The first in another new class of agents - the selective cannabinoid receptor antagonist rimonabant [132] - was licensed in Europe in 2006, with the European Medicines Agency recommending the suspension of its marketing authorization in late 2008 because of an unacceptable risk of psychiatric disorders. In trials, rimonabant reduced waist circumference, a proxy for visceral adiposity [133], and improved lipid profiles [134] and glycaemic control in pre-diabetic and diabetic subjects [135]. However, as for many other clinical studies of obesity treatments, high drop-out rates made some of the data difficult to interpret [136]. Another member of this class, taranabant, was recently discontinued in phase III trials because of psychiatric and gastrointestinal side effects.

\section{Drugs in Development}

Another new drug currently in clinical trials, tesofensine, reduces body weight, glycated haemoglobin and insulin levels while raising adiponectin levels compared with placebo in non-diabetic adults in the context of an energy-reduced diet [137]. However, in this phase II study, the drug increased heart rate and there was a small rise in blood pressure at the highest dose. Closer scrutiny of tesofensine, which inhibits pre-synaptic uptake of monoamines, is required. Increased blood pressure is a limitation of sibutramine, a less potent weight-reducing drug with a similar mode of action [138]. This example raises an important therapeutic issue: sometimes drug therapy directed at one aspect of the metabolic syndrome may inadvertently exacerbate another, thereby offsetting the net clinical benefit. A prominent example is found in the use of $\beta$-blockers and diuretics for hypertension. Classic $\beta$-blockers such as atenolol promote weight gain, worsen insulin resistance and glycaemic control, and cause deleterious alterations in plasma lipids [139]. Diuretics, especially at higher doses, also have adverse metabolic effects. The risk of developing new-onset diabetes is increased with $\beta$-blockers and diuretics relative to other classes, some of which may exert a protective effect [140]. For these reasons, expert guidelines suggest the preferential use of drugs acting on the RAS and calcium channel blockers rather than $\beta$-blockers and diuretics $[141,142]$.

Recently, the novel lipid modifying drug torcetrapib (in combination with atorvastatin) was found to increase cardiovascular mortality instead of providing protection against atherosclerosis. This was observed even though the drug, a cholesteryl ester transfer protein inhibitor, increased HDL cholesterol levels. Off-target mineralocorticoid-mediated effects have emerged as the likely cause of this disastrous outcome. Thus, subjects treated with torcetrapib + atorvastatin had higher systolic blood pressure and plasma sodium levels, and lower levels of potassium [143]. The observation that the use of RAS inhibitors tended to aggravate increases in blood pressure highlights the need to consider the potential for adverse drug-drug interactions when treating complex metabolic disorders.

Several additional classes of novel drugs are in development that may find application in the prevention of the chronic microvascular and macrovascular complications 
Fig. 1. Schematic representation of the main interactions between microvascular and macrovascular disease. Steps at which proven or hypothetical therapeutic intervention may be possible are indicated. Note that additional interactions and mechanisms may be operative, but these have not been included for the sake of clarity.

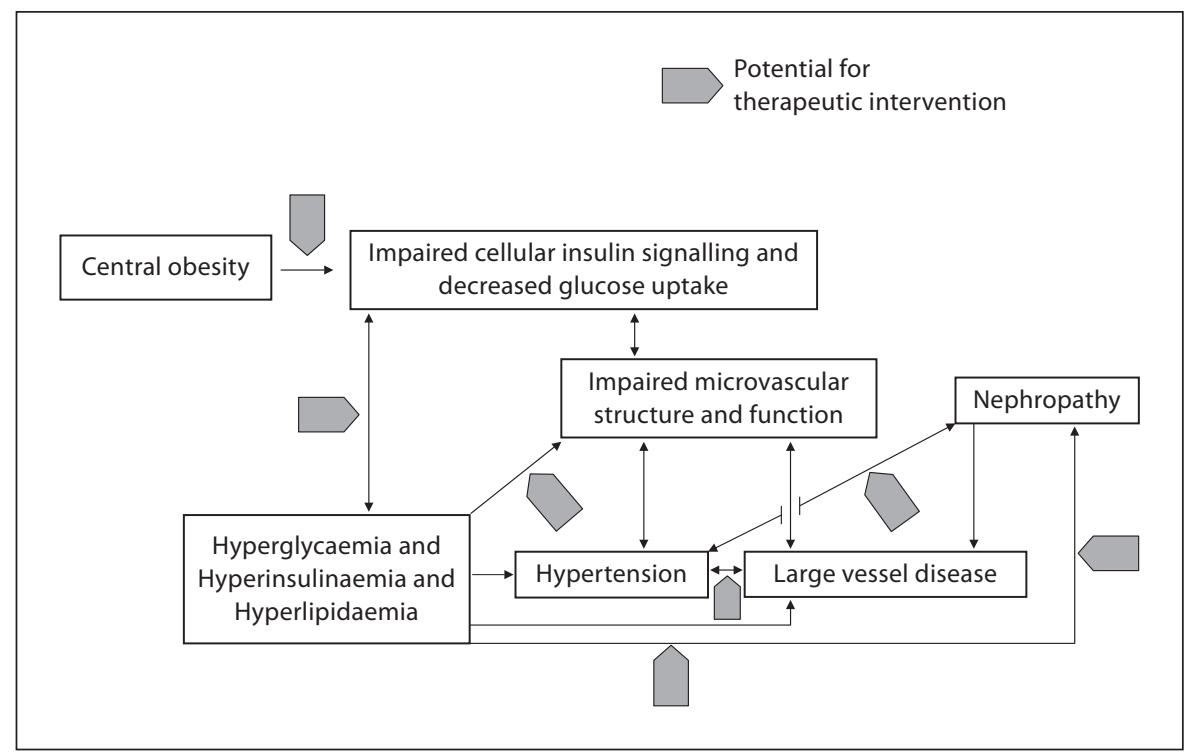

of diabetes and the metabolic syndrome [144]. Included are compounds that inhibit formation of advanced glycation end-products, cleave cross-links or reverse interactions with the receptor for advanced glycation end-products. Pharmacological inhibitors of the hexosamine pathway, strategies to reduce reactive oxygen species and blockade of growth factors or intracellular messengers of cellular differentiation are also under investigation [144].

\section{Conclusions and Recommendations}

The metabolic syndrome is set to affect large numbers of ever-younger people as the prevalence of obesity rises across the world. Affected individuals face unprecedented levels of exposure to multiple risk factors for vascular disease including a substantially increased lifelong risk of developing type 2 diabetes. Mounting evidence suggests that the metabolic syndrome adds to the burden of vascular damage associated with diabetes. When diabetes is already present, other components of the metabolic syndrome may nonetheless enhance the risk of microvascular and macrovascular disease. Moreover, microvascular dysfunction may promote the progression of macrovascular disease through direct and indirect mechanisms (fig. 1). We suggest that a synthesis of current and emerging therapeutic interventions might provide the basis for an improved strategy aimed at preventing microangiopathy-related morbidity and mortality. As adjuncts to lifestyle measures, the early use of anti-diabetic drugs with

vasculoprotective properties is logical and attractive, but requires further investigation. Newer drugs are more expensive and inevitably suffer from having less robust safety data than well-established agents. However, new drugs, if they prove safe in the long-term, might prove cost-effective if initiated earlier in high-risk subjects with states of pre-diabetes [145]. Carefully designed clinical trials will be required to assess the risk-benefit and economic considerations of these approaches.

References

1 Eckel RH, Grundy SM, Zimmet PZ: The metabolic syndrome. Lancet 2005;365:14151428.

2 Alberti KG, Zimmet P, Shaw J: The metabolic syndrome - a new worldwide definition. Lancet 2005;366:1059-1062.

-3 Grundy SM: Metabolic syndrome: connecting and reconciling cardiovascular and diabetes worlds. J Am Coll Cardiol 2006;47: 1093-1100.

4 Grundy SM, Cleeman JI, Daniels SR, et al: Diagnosis and management of the metabolic syndrome: an American Heart Association/ National Heart, Lung, and Blood Institute scientific statement. Curr Opin Cardiol 2006;21:1-6.

5 De Ferranti SD, Osganian SK: Epidemiology of paediatric metabolic syndrome and type 2 diabetes mellitus. Diab Vasc Dis Res 2007;4: 285-296

6 Gardner M, Gardner DW, Sowers JR: The cardiometabolic syndrome in the adolescent. Pediatr Endocrinol Rev 2008;5(suppl 4):964-968. 
7 Bao W, Srinivasan SR, Wattigney WA, Berenson GS: Persistence of multiple cardiovascular risk clustering related to syndrome $\mathrm{X}$ from childhood to young adulthood: the Bogalusa Heart Study. Arch Intern Med 1994;154:1842-1847.

$>8$ Weiss R, Dziura J, Burgert TS, et al: Obesity and the metabolic syndrome in children and adolescents. N Engl J Med 2004;350:23622374.

$\checkmark 9$ Pinhas-Hamiel O, Zeitler P: Acute and chronic complications of type 2 diabetes mellitus in children and adolescents. Lancet 2007;369:1823-1831.

10 Pirart J: Diabetes mellitus and its degenerative complications: a prospective study of 4,400 patients observed between 1947 and 1973 (3rd and last part). Diabete Metab 1977; 3:245-256.

11 Intensive blood-glucose control with sulphonylureas or insulin compared with conventional treatment and risk of complications in patients with type 2 diabetes (UKPDS 33): UK Prospective Diabetes Study (UKPDS) Group. Lancet 1998;352:837-853.

12 Nathan DM: Long-term complications of diabetes mellitus. N Engl J Med 1993;328: 1676-1685.

13 Molitch ME, DeFronzo RA, Franz MJ, et al: Nephropathy in diabetes. Diabetes Care 2004;27(suppl 1):S79-S83.

14 Jawa A, Kcomt J, Fonseca VA: Diabetic nephropathy and retinopathy. Med Clin North Am 2004;88:1001-1036, xi.

-15 Krishnan AV, Kiernan MC: Uremic neuropathy: clinical features and new pathophysiological insights. Muscle Nerve 2007;35: 273-290.

-16 McGowan T, McCue P, Sharma K: Diabetic nephropathy. Clin Lab Med 2001;21:111146.

17 Wiernsperger N, Nivoit P, De Aguiar LG, Bouskela E: Microcirculation and the metabolic syndrome. Microcirculation 2007;14: 403-438.

18 Stokes KY, Granger DN: The microcirculation: a motor for the systemic inflammatory response and large vessel disease induced by hypercholesterolaemia? J Physiol 2005;562: 647-653.

19 Stepp DW, Pollock DM, Frisbee JC: Lowflow vascular remodeling in the metabolic syndrome X. Am J Physiol Heart Circ Physiol 2004;286:H964-H970.

20 Frisbee JC: Hypertension-independent microvascular rarefaction in the obese Zucker rat model of the metabolic syndrome. Microcirculation 2005; 12:383-392.

-21 de Jongh RT, Serné EH, Ijzerman RG, de Vries G, Stehouwer CD: Impaired microvascular function in obesity: implications for obesity-associated microangiopathy, hypertension, and insulin resistance. Circulation 2004;109:2529-2535.
22 Clerk LH, Vincent MA, Jahn LA, Liu Z, Lindner JR, Barrett EJ: Obesity blunts insulin-mediated microvascular recruitment in human forearm muscle. Diabetes 2006;55: 1436-1442.

23 Frisbee JC: Obesity, insulin resistance, and microvessel density. Microcirculation 2007; 14:289-298.

24 Kingwell BA, Formosa M, Muhlmann M, Bradley SJ, McConell GK: Type 2 diabetic individuals have impaired leg blood flow responses to exercise: role of endothelium-dependent vasodilation. Diabetes Care 2003; 26:899-904.

-25 Bitar MS, Wahid S, Mustafa S, Al-Saleh E, Dhaunsi GS, Al-Mulla F: Nitric oxide dynamics and endothelial dysfunction in type II model of genetic diabetes. Eur J Pharmacol 2005;511:53-64

26 Gudbjornsdottir S, Sjostrand M, Strindberg L, Lonnroth P: Decreased muscle capillary permeability surface area in type 2 diabetic subjects. J Clin Endocrinol Metab 2005;90: 1078-1082.

-27 Marin P, Andersson B, Krotkiewski M, Bjorntorp P: Muscle fiber composition and capillary density in women and men with NIDDM. Diabetes Care 1994;17:382-386.

28 Chung TW, Liu AG, Yu JH: Increased red cell rigidity might affect retinal capillary blood flow velocity and oxygen transport efficiency in type II diabetes. Diabetes Res 1993;23: 75-82.

29 Goldin A, Beckman JA, Schmidt AM, Creager MA: Advanced glycation end products: sparking the development of diabetic vascular injury. Circulation 2006;114:597-605.

-30 Scognamiglio R, Negut C, De Kreutzenberg SV, Tiengo A, Avogaro A: Postprandial myocardial perfusion in healthy subjects and in type 2 diabetic patients. Circulation 2005; 112:179-184.

31 Krentz AJ, Clough G, Byrne CD: Interactions between microvascular and macrovascular disease in diabetes: pathophysiology and therapeutic implications. Diabetes Obes Metab 2007;9:781-791.

32 Meguid El Nahas A, Bello AK: Chronic kidney disease: the global challenge. Lancet 2005;365:331-340.

33 Hypertension in Diabetes Study (HDS): I. Prevalence of hypertension in newly presenting type 2 diabetic patients and the association with risk factors for cardiovascular and diabetic complications. J Hypertens 1993;11:309-317.

$>34$ Jenkins AJ, Rowley KG, Lyons TJ, Best JD, Hill MA, Klein RL: Lipoproteins and diabetic microvascular complications. Curr Pharm Des 2004;10:3395-3418.

$>35$ Keech A, Simes RJ, Barter P, et al: Effects of long-term fenofibrate therapy on cardiovascular events in 9795 people with type 2 diabetes mellitus (the FIELD study): randomised controlled trial. Lancet 2005;366: 1849-1861.
36 Tesfaye S, Chatuvedi N, Eaton SEM, et al: Vascular risk factors and diabetic neuropathy. N Engl J Med 2005;352:592-597.

37 McGill M, Molyneaux L, Twigg SM, Yue DK: The metabolic syndrome in type 1 diabetes: does it exist and does it matter? J Diabetes Complications 2008;22:18-23.

38 Isomaa B, Henricsson M, Almgren P, Tuomi T, Taskinen MR, Groop L: The metabolic syndrome influences the risk of chronic complications in patients with type II diabetes. Diabetologia 2001;44:1148-1154.

39 Costa LA, Canani LH, Lisboa HR, Tres GS, Gross JL: Aggregation of features of the metabolic syndrome is associated with increased prevalence of chronic complications in Type 2 diabetes. Diabet Med 2004;21:252-255.

$\checkmark 40$ Abdul-Ghani M, Nawaf G, Nawaf F, Itzhak B, Minuchin O, Vardi P: Increased prevalence of microvascular complications in type 2 diabetes patients with the metabolic syndrome. Isr Med Assoc J 2006;8:378-382.

41 Bonadonna RC, Cucinotta D, Fedele D, Riccardi G, Tiengo A: The metabolic syndrome is a risk indicator of microvascular and macrovascular complications in diabetes: results from Metascreen, a multicenter diabetes clinic-based survey. Diabetes Care 2006;29: 2701-2707.

-42 Cull CA, Jensen CC, Retnakaran R, Holman RR: Impact of the metabolic syndrome on macrovascular and microvascular outcomes in type 2 diabetes mellitus: United Kingdom Prospective Diabetes Study 78. Circulation 2007;116:2119-2126.

43 Gabir MM, Hanson RL, Dabelea D, et al: Plasma glucose and prediction of microvascular disease and mortality: evaluation of 1997 American Diabetes Association and 1999 World Health Organization criteria for diagnosis of diabetes. Diabetes Care 2000; 23:1113-1118.

44 Expert Committee on the Diagnosis and Classification of Diabetes Mellitus: Report of the expert committee on the diagnosis and classification of diabetes mellitus. Diabetes Care 2002;25:S5-S20.

45 Haffner SJ, Cassells H: Hyperglycemia as a cardiovascular risk factor. Am J Med 2003; 115(suppl 8A):6S-11S.

46 Nesto RW: Correlation between cardiovascular disease and diabetes mellitus: current concepts. Am J Med 2004;116(suppl 5A):11S22S.

47 Gerstein HC, Yusuf S: Dysglycaemia and risk of cardiovascular disease. Lancet 1996;347: 949-950.

48 Khaw KT, Wareham N, Luben R, et al: Glycated haemoglobin, diabetes, and mortality in men in Norfolk cohort of European Prospective Investigation of Cancer and Nutrition (EPIC-Norfolk). BMJ 2001;322:15-18.

49 Alberti KG: Impaired glucose tolerance: what are the clinical implications? Diabetes Res Clin Pract 1998;40(suppl):S3-S8. 
50 Singleton JR, Smith AG, Russell JW, Feldman EL: Microvascular complications of impaired glucose tolerance. Diabetes 2003;52: 2867-2873.

51 Garcia Soriano F, Virag L, Jagtap P, et al: Diabetic endothelial dysfunction: the role of poly(ADP-ribose) polymerase activation. Nat Med 2001;7:108-113.

52 Heine RJ, Balkau B, Ceriello A, Del Prato S, Horton ES, Taskinen MR: What does postprandial hyperglycaemia mean? Diabet Med 2004;21:208-213.

53 Su Y, Liu XM, Sun YM, et al: The relationship between endothelial dysfunction and oxidative stress in diabetes and prediabetes. Int J Clin Pract 2008;62:877-882.

54 Nguyen TT, Wong TY: Retinal vascular manifestations of metabolic disorders. Trends Endocrinol Metab 2006;17:262-268.

55 Wong TY, Duncan BB, Golden SH, et al: Associations between the metabolic syndrome and retinal microvascular signs: the Atherosclerosis Risk In Communities study. Invest Ophthalmol Vis Sci 2004;45:2949-2954.

56 Kawasaki R, Tielsch JM, Wang JJ, et al: The metabolic syndrome and retinal microvascular signs in a Japanese population: the Funagata study. Br J Ophthalmol 2008;92:161166.

$\checkmark 57$ Lee RH, Dellon AL: Insulin resistance: does it play a role in peripheral neuropathy? Diabetes Care 1999;22:1914-1915.

58 Krentz AJ, Honigsberger L, Nattrass M: Selection of patients with symptomatic diabetic neuropathy for clinical trials. Diabete Metab 1989; 15:416-419.

59 Cameron NE, Cotter MA: Metabolic and vascular factors in the pathogenesis of diabetic neuropathy. Diabetes 1997;46(suppl 2): S31-S37.

60 Singleton JR, Smith AG: Therapy insight: neurological complications of prediabetes. Nat Clin Pract Neurol 2006;2:276-282.

-61 Smith AG, Singleton JR: Impaired glucose tolerance and neuropathy. Neurologist 2008; 14:23-29.

-62 Saenz de Tejada I, Goldstein I, Azadzoi K, Krane RJ, Cohen RA: Impaired neurogenic and endothelium-mediated relaxation of penile smooth muscle from diabetic men with impotence. N Engl J Med 1989;320:10251030.

63 Solomon H, Man JW, Jackson G: Erectile dysfunction and the cardiovascular patient: endothelial dysfunction is the common denominator. Heart 2003;89:251-253.

-64 Fung MM, Bettencourt R, Barrett-Connor E: Heart disease risk factors predict erectile dysfunction 25 years later: the Rancho Bernardo Study. J Am Coll Cardiol 2004;43: 1405-1411.

-65 Turner RC: The UK Prospective Diabetes Study: a review. Diabetes Care 1998;21(suppl 3):C35-C38.
66 Harris MI, Klein R, Welborn TA, Knuiman MW: Onset of NIDDM occurs at least 4-7 yr before clinical diagnosis. Diabetes Care 1992;15:815-819.

67 Alberti KG: Blood metabolites in the diagnosis and treatment of diabetes mellitus. Postgrad Med J 1973;49(suppl 7):955-963.

$68 \mathrm{He}$ W, Miao FJ, Lin DC, et al: Citric acid cycle intermediates as ligands for orphan G-protein-coupled receptors. Nature 2004;429: 188-193.

69 Lowell BB, Shulman GI: Mitochondrial dysfunction and type 2 diabetes. Science 2005; 307:384-387.

70 Serne EH, de Jongh RT, Eringa EC, Ijzerman RG, de Boer MP, Stehouwer CD: Microvascular dysfunction: causative role in the association between hypertension, insulin resistance and the metabolic syndrome? Essays Biochem 2006;42:163-176.

71 De Jongh RT, Clark AD, Ijzerman RG, Serne EH, De Vries G, Stehouwer CD: Physiological hyperinsulinaemia increases intramuscular microvascular reactive hyperaemia and vasomotion in healthy volunteers. Diabetologia 2004;47:978-986.

72 Clough G, Turzniecka M, Walter M, et al: Muscle microvascular function in central obesity is related to muscle insulin insenstivity but is not reversed by high-dose statin treatment. Diabetes 2009, E-pub ahead of print.

73 Bohlen HG: Mechanisms for early microvascular injury in obesity and type II diabetes. Curr Hypertens Rep 2004;6:60-65.

74 Frisbee JC: Reduced nitric oxide bioavailability contributes to skeletal muscle microvessel rarefaction in the metabolic syndrome. Am J Physiol Regul Integr Comp Physiol 2005;289:R307-R316.

75 de Jongh RT, Serne EH, Ijzerman RG, de Vries G, Stehouwer CD: Free fatty acid levels modulate microvascular function: relevance for obesity-associated insulin resistance, hypertension, and microangiopathy. Diabetes 2004;53:2873-2882.

76 Krentz AJ, Singh BM, Hale PJ, Robertson DA, Nattrass M: Basal intermediary metabolism in impaired glucose tolerance and morbid obesity. Diabetes Res 1992;20:51-60.

77 Trujillo ME, Scherer PE: Adipose tissue-derived factors: impact on health and disease. Endocr Rev 2006;27:762-778.

78 Elbatarny HS, Netherton SJ, Ovens JD, Ferguson AV, Maurice DH: Adiponectin, ghrelin, and leptin differentially influence human platelet and human vascular endothelial cell functions: implication in obesityassociated cardiovascular diseases. Eur J Pharmacol 2007;558:7-13.

79 Jayasena CN, Bloom SR: Role of gut hormones in obesity. Endocrinol Metab Clin North Am 2008;37:769-787, xi.

80 Tigno XT, Selaru IK, Angeloni SV, Hansen BC: Is microvascular flow rate related to ghrelin, leptin and adiponectin levels? Clin Hemorheol Microcirc 2003;29:409-416.
81 Hadjadj S, Pean F, Gallois Y, et al: Different patterns of insulin resistance in relatives of type 1 diabetic patients with retinopathy or nephropathy: the Genesis France-Belgium Study. Diabetes Care 2004;27:2661-2668.

82 Barker DJ, Osmond C, Golding J, Kuh D, Wadsworth ME: Growth in utero, blood pressure in childhood and adult life, and mortality from cardiovascular disease. BMJ 1989;298:564-567.

$>83$ Leeson CP, Kattenhorn M, Morley R, Lucas A, Deanfield JE: Impact of low birth weight and cardiovascular risk factors on endothelial function in early adult life. Circulation 2001;103:1264-1268

84 Goodfellow J, Bellamy MF, Gorman ST, et al: Endothelial function is impaired in fit young adults of low birth weight. Cardiovasc Res 1998;40:600-606.

85 Martin H, Gazelius B, Norman M: Impaired acetylcholine-induced vascular relaxation in low birth weight infants: implications for adult hypertension? Pediatr Res 2000;47: 457-462.

$>86$ Goh KL, Shore AC, Quinn M, Tooke JE: Impaired microvascular vasodilatory function in 3-month-old infants of low birth weight. Diabetes Care 2001;24:1102-1107.

87 Norman M, Martin H: Preterm birth attenuates association between low birth weight and endothelial dysfunction. Circulation 2003;108:996-1001.

$>88$ Williams R, Van Gaal L, Lucioni C: Assessing the impact of complications on the costs of Type II diabetes. Diabetologia 2002;45: S13-S17.

89 Haffner S: Diabetes and the metabolic syndrome - when is it best to intervene to prevent? Atheroscler Suppl 2006;7:3-10.

$>90$ Kim JA, Montagnani M, Koh KK, Quon MJ: Reciprocal relationships between insulin resistance and endothelial dysfunction: molecular and pathophysiological mechanisms. Circulation 2006;113:1888-1904.

$\checkmark 1$ Baron AD: Insulin resistance and vascular function. J Diabetes Complications 2002;16: 92-102.

92 Vincent MA, Clerk LH, Lindner JR, et al: Microvascular recruitment is an early insulin effect that regulates skeletal muscle glucose uptake in vivo. Diabetes 2004;53:1418-1423.

-93 Sobel BE, Woodcock-Mitchell J, Schneider DJ, Holt RE, Marutsuka K, Gold H: Increased plasminogen activator inhibitor type 1 in coronary artery atherectomy specimens from type 2 diabetic compared with nondiabetic patients: a potential factor predisposing to thrombosis and its persistence. Circulation 1998;97:2213-2221.

$\checkmark 94$ Takebayashi K, Aso Y, Inukai T: Initiation of insulin therapy reduces serum concentrations of high-sensitivity C-reactive protein in patients with type 2 diabetes. Metabolism 2004;53:693-699. 
-95 Vehkavaara S, Yki-Jarvinen H: 3.5 years of insulin therapy with insulin glargine improves in vivo endothelial function in type 2 diabetes. Arterioscler Thromb Vasc Biol 2004;24:325-330.

96 Tamminen MK, Westerbacka J, Vehkavaara S, Yki-Jarvinen $\mathrm{H}$ : Insulin therapy improves insulin actions on glucose metabolism and aortic wave reflection in type 2 diabetic patients. Eur J Clin Invest 2003;33: 855-860.

$\checkmark 97$ Collins R, Armitage J, Parish S, Sleigh P, Peto R: MRC/BHF Heart Protection Study of cholesterol-lowering with simvastatin in 5963 people with diabetes: a randomised placebo-controlled trial. Lancet 2003;361: 2005-2016.

$\checkmark 98$ Krentz AJ: Lipoprotein abnormalities and their consequences for patients with type 2 diabetes. Diabetes Obes Metab 2003;5(suppl 1):S19-S27.

$\checkmark 99$ Armitage J, Bowman L: Cardiovascular outcomes among participants with diabetes in the recent large statin trials. Curr Opin Lipidol 2004;15:439-446.

$\checkmark 100$ Colhoun HM, Betteridge DJ, Durrington PN, et al: Primary prevention of cardiovascular disease with atorvastatin in type 2 diabetes in the Collaborative Atorvastatin Diabetes Study (CARDS): multicentre randomised placebo-controlled trial. Lancet 2004;364:685-696.

-101 Mogensen CE, Cooper ME: Diabetic renal disease: from recent studies to improved clinical practice. Diabet Med 2004;21:417.

102 Yamagishi S, Matsui T, Sato T, Takeuchi M: Protective role of pravastatin in the pathogenesis of the metabolic syndrome. Med Hypotheses 2006;66:609-611.

-103 Fegan PG, Shore AC, Mawson D, Tooke JE, MacLeod KM: Microvascular endothelial function in subjects with Type 2 diabetes and the effect of lipid-lowering therapy. Diabet Med 2005;22:1670-1676.

104 Kastelein JJ: Refocusing on use of cholesteryl ester transfer protein inhibitors. Am J Cardiol 2007;100:n47-n52.

-105 Tight blood pressure control and risk of macrovascular and microvascular complications in type 2 diabetes: UKPDS 38. UK Prospective Diabetes Study Group. BMJ 1998;317:703-713.

-106 McVeigh GE, Plumb R, Hughes S: Vascular abnormalities in hypertension: cause, effect, or therapeutic target? Curr Hypertens Rep 2004;6:171-176.

-107 McFarlane SI, Kumar A, Sowers JR: Mechanisms by which angiotensin-converting enzyme inhibitors prevent diabetes and cardiovascular disease. Am J Cardiol 2003;91: $30 \mathrm{H}-37 \mathrm{H}$.

108 Bosch J, Yusuf S, Gerstein HC, et al: Effect of ramipril on the incidence of diabetes. $\mathrm{N}$ Engl J Med 2006;355:1551-1562.
109 Effect of intensive blood-glucose control with metformin on complications in overweight patients with type 2 diabetes (UKPDS 34). UK Prospective Diabetes Study (UKPDS) Group. Lancet 1998;352:854865.

110 Wiernsperger NF, Bouskela E: Microcirculation in insulin resistance and diabetes: more than just a complication. Diabetes Metab 2003;29:6S77-6S87.

111 Holman RR, Paul SK, Bethel MA, Matthews DR, Neil HA: 10-year follow-up of intensive glucose control in type 2 diabetes. N Engl J Med 2008;359:1577-1589.

112 Semple RK, Chatterjee VK, O’Rahilly S: PPAR-gamma and human metabolic disease. J Clin Invest 2006;116:581-589.

113 Martens FM, Visseren FL, Lemay J, de Koning EJ, Rabelink TJ: Metabolic and additional vascular effects of thiazolidinediones. Drugs 2002;62:1463-1480.

114 Viberti G: Thiazolidinediones - benefits on microvascular complications of type 2 diabetes. J Diabetes Complications 2005;19: 168-177.

115 Forst T, Lubben G, Hohberg C, et al: Influence of glucose control and improvement of insulin resistance on microvascular blood flow and endothelial function in patients with diabetes mellitus type 2 . Microcirculation 2005;12:543-550.

116 Artwohl M, Furnsinn C, Waldhausl W, et al: Thiazolidinediones inhibit proliferation of microvascular and macrovascular cells by a PPAR-gamma-independent mechanism. Diabetologia 2005;48:586-594.

117 Bagi Z, Koller A, Kaley G: PPARgamma activation, by reducing oxidative stress, increases NO bioavailability in coronary arterioles of mice with Type 2 diabetes. Am J Physiol Heart Circ Physiol 2004;286:H742H748.

118 Knowler WC, Barrett-Connor E, Fowler SE, et al: Reduction in the incidence of type 2 diabetes with lifestyle intervention or metformin. N Engl J Med 2002;346:393403.

119 DREAM (Diabetes REduction Assessment with ramipril and rosiglitazone Medication) Trial Investigators, Gerstein $\mathrm{HC}, \mathrm{Yu}-$ suf S, Bosch J, Pogue J, Sheridan P, Dinccag N, Hanefeld M, Hoogwerf B, Laakso M, Mohan V, Shaw J, Zinman B, Holman RR: Effect of rosiglitazone on the frequency of diabetes in patients with impaired glucose tolerance or impaired fasting glucose: a randomised controlled trial. Lancet 2006; 368:1096-1105.

120 Buchanan TA, Xiang AH, Peters RK, et al: Preservation of pancreatic beta-cell function and prevention of type 2 diabetes by pharmacological treatment of insulin resistance in high-risk Hispanic women. Diabetes 2002;51:2796-2803.

-121 Bell DS: Beta-cell rejuvenation with thiazolidinediones. Am J Med 2003;115(suppl $8 \mathrm{~A}): 20 \mathrm{~S}-23 \mathrm{~S}$.
122 Dormandy JA, Charbonnel B, Eckland DJ, et al: Secondary prevention of macrovascular events in patients with type 2 diabetes in the PROactive Study (PROspective pioglitAzone Clinical Trial In macroVascular Events): a randomised controlled trial. Lancet 2005;366:1279-1289.

123 Yki-Jarvinen $\mathrm{H}$ : The PROactive study: some answers, many questions. Lancet 2005;366:1241-1242.

124 Nissen SE, Wolski K: Effect of rosiglitazone on the risk of myocardial infarction and death from cardiovascular causes. N Engl J Med 2007;356:2457-2471.

125 Singh S, Loke YK, Furberg CD: Long-term risk of cardiovascular events with rosiglitazone: a meta-analysis. JAMA 2007;298: 1189-1195.

126 Lincoff AM, Wolski K, Nicholls SJ, Nissen SE: Pioglitazone and risk of cardiovascular events in patients with type 2 diabetes mellitus: a meta-analysis of randomized trials. JAMA 2007;298:1180-1188.

127 Nesto RW, Bell D, Bonow RO, et al: Thiazolidinedione use, fluid retention, and congestive heart failure: a consensus statement from the American Heart Association and American Diabetes Association. October 7, 2003. Circulation 2003;108:2941-2948.

128 Meier C, Kraenzlin ME, Bodmer M, Jick SS, Jick H, Meier CR: Use of thiazolidinediones and fracture risk. Arch Intern Med 2008; 168:820-825.

129 Grundy SM: Drug therapy of the metabolic syndrome: minimizing the emerging crisis in polypharmacy. Nat Rev Drug Discov 2006;5:295-309.

130 Nissen SE, Wolski K, Topol EJ: Effect of muraglitazar on death and major adverse cardiovascular events in patients with type 2 diabetes mellitus. JAMA 2005;294:25812586.

131 Evans RM, Barish GD, Wang YX: PPARs and the complex journey to obesity. Nat Med 2004;10:355-361.

132 Bailey CJ: Drugs on the horizon for diabesity. Curr Diab Rep 2005;5:353-359.

133 Van Gaal LF, Rissanen AM, Scheen AJ, Ziegler O, Rossner S: Effects of the cannabinoid-1 receptor blocker rimonabant on weight reduction and cardiovascular risk factors in overweight patients: 1-year experience from the RIO-Europe Study. Lancet 2005;365:1389-1397.

134 Despres JP, Golay A, Sjostrom L: Effects of rimonabant on metabolic risk factors in overweight patients with dyslipidemia. $\mathrm{N}$ Engl J Med 2005;353:2121-2134.

135 Gelfand EV, Cannon CP: Rimonabant: a cannabinoid receptor type 1 blocker for management of multiple cardiometabolic risk factors. J Am Coll Cardiol 2006;47: 1919-1926. 
136 Simons-Morton DG, Obarzanek E, Cutler JA: Obesity research: limitations of methods, measurements, and medications. JAMA 2006;295:826-828.

-137 Astrup A, Madsbad S, Breum L, Jensen TJ, Kroustrup JP, Larsen TM: Effect of tesofensine on bodyweight loss, body composition, and quality of life in obese patients: a randomised, double-blind, placebo-controlled trial. Lancet 2008;372:1906-1913.

138 Arterburn DE, Crane PK, Veenstra DL: The efficacy and safety of sibutramine for weight loss: a systematic review. Arch Intern Med 2004;164:994-1003.
139 Wenzel UO, Krebs C: Management of arterial hypertension in obese patients. Curr Hypertens Rep 2007;9:491-497.

140 Elliott WJ, Meyer PM: Incident diabetes in clinical trials of antihypertensive drugs: a network meta-analysis. Lancet 2007;369: 201-207.

-141 Williams B, Poulter NR, Brown MJ, et al Guidelines for management of hypertension: report of the fourth working party of the British Hypertension Society, 2004BHS IV. J Hum Hypertens 2004;18:139185.

142 Redon J, Cifkova R, Laurent S, et al: The metabolic syndrome in hypertension: European Society of Hypertension position statement. J Hypertens 2008;26:18911900 .
143 Vergeer M, Bots ML, van Leuven SI, et al: Cholesteryl ester transfer protein inhibitor torcetrapib and off-target toxicity: a pooled analysis of the rating atherosclerotic disease change by imaging with a new CETP inhibitor (RADIANCE) trials. Circulation 2008;118:2515-2522.

144 Soro-Paavonen A, Forbes JM: Novel therapeutics for diabetic micro- and macrovascular complications. Curr Med Chem 2006; 13:1777-1788.

145 Herman WH, Hoerger TJ, Brandle M, et al: The cost-effectiveness of lifestyle modification or metformin in preventing type 2 diabetes in adults with impaired glucose tolerance. Ann Intern Med 2005;142:323-332. 